\title{
Daily Harvested Energy of Cadmium Telluride Thin Film Photovoltaic
}

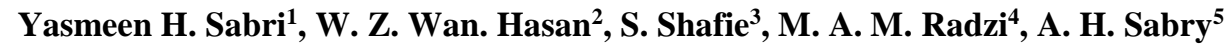 \\ 1,2,4,5 Department of Electrical and Electronic Engineering, University Putra Malaysia (UPM), Malaysia \\ ${ }^{3}$ Institute of Advance Technology (ITMA), University Putra Malaysia (UPM). Malaysia
}

\section{Article Info \\ Article history: \\ Received Feb 2, 2018 \\ Revised Apr 5, 2018 \\ Accepted Apr 20, 2018 \\ Keywords: \\ Photovoltaic systems \\ PV Modeling \\ PV thin-Film \\ Real-Time monitoring \\ System efficiency}

\begin{abstract}
The power generated by solar photovoltaic (PV) is highly affected by the weather environment. Thin-Film solar module of cadmium telluride (CdTe) is one of the Semi-transparent PV (STPV) that can be employed in a wide application range as a means to sunlight permeability while supplying solar electrical energy with some shading which also preferable in hot areas. The system behavior and the forecast of a STPV harvested energy requires an accurate and reliable discribtion for the power pattern rate during the day time. This research presents a real-time daily measurements for CdTe PV modules that serve the system design, prediction, and modeling. Multilayer and single installation categories are configured to be experimentally tested at different weather conditions (temperature and irradiance). The measurements were conducted at UPM University, Serdang, Malaysia, where a 6 different modules are expreinced. A wireless monitoring system with high sampling frequency employed for this purose. The results show an efficiency of 2.51 as a maximum in cloudy day conditions, while the harvested daily energy show that a multi-layer configuration may only be effective when the transparency is high. This new generation of PV module is similar to that for Silicon-based PV but it has threshold value to start power generating and promises for efficient sustainable building materials.
\end{abstract}

Copyright $@ 2018$ Institute of Advanced Engineering and Science. All rights reserved.

\section{Corresponding Author:}

W. Z. Wan. Hasan,

Department of Electrical and Electronic Engineering,

University Putra Malaysia (UPM), Malaysia.

Email: wanzuha@upm.edu.my

\section{INTRODUCTION}

The success of any new technology depends on the ability to demonstrate its actual advantages. Because there is no direct experience with its application, the effectiveness of a new technology is often assessed on the basis of the results obtained from predictive performance tools. A good predictive tool should allow the designer to optimize the performance and maximize the cost-effectiveness of a system before installation. This optimization is especially significant in the field of renewable energy systems because their effectiveness is usually affected by many erratic physical parameters [1]. The performance testing of PV modules at outdoor conditions is required to have an accurate estimation of output of PV modules under specific climate [2]. Thin-film solar cells enable a strong reduction of the amount of silicon needed to produce photovoltaic panels but their efficiency lowers [3]. CdTe cells are a type of the semiconductor thin film that has the permitting for lower production costs. CdTe technology has done the highest production level of all the thin film technologies [4]. The design engineers considered the Predicting of a performance of PV panels is essential [5]. Although thin-film photovoltaic (PV) modules have been in production for decades, the characterization of their performance, both outdoors and under a synthetic light. The Standard Test Conditions (STC) take in irradiance of a clear summer day and the module temperature of a clear winter day. These measurement conditions clearly do not represent real operating conditions of PV at the site of 
installation. Therefore the Modelling of solar PV could be useful in predicting the important characteristics of solar PV modules under real time [6].

The generation of power from solar energy is very erratic due to its highly dependence on climate, seasonal changes, geographical site, time of the day, orientation and attitude of panel [7]. For the optimum design of PV power systems, it is better to measure their long term performances at the site of installation. Therefore, some researchers utilizing measured temperature coefficients of the characteristic parameters of the (I-V) curve, sort of then extrapolating the curve same [8]. Through the real-time monitoring for some parameters important, like the electrical characteristics, sun irradiation and ambient parameters for panels or each panel, is carried out. Monitoring and analysis of these parameters will create the system appropriate to perform pertinent services. The monitoring of photovoltaic system and optimization of the energy they produce is a key issue in order to warranty this type of systems can achieve the objective of significantly contributing to supply the ever increasing request of electrical power [9]. A lux meters, thermometers, and multimeters thesis are a type of analog instruments and manual measurements used for measurements had been done previously. Such type of measurements can't achieve the current requirements in the period of the time duration and accuracy. The effective resolution for this problem is to improve a data logger.

There are various research areas that need to be explored on solar PV application as it is the question mark to everyone involved in the solar PV business whether the technology can be the best energy source for Malaysia condition. This study presents a unique platform interface for Solar PV Monitoring Station (SPMS) to capture measurement from multiple sources and analyze visually in real-time and synchronize mode which is the crucial aspect for rapid fluctuating data flow. The performance monitoring of a PV system, so, requires that the appropriate weather parameters be recorded. The utilization of the photovoltaic (PV) generation of electric power depends on reducing the cost of the power generated and improving the energy efficiency of PV systems. The PV system power output is primarily influenced by the weather, the solar irradiance and the module temperature [10].

Data procuration systems are widely utilized in renewable energy implementation in order that collects data as regards the system performance for evaluation purposes [11]. The passing system energy efficiency at any date and time is defined as the ratio of the output power to the solar irradiance per unit area of the solar PV panel [12].

The based on electrical parameters directly acquired from the solar field. In principle, the performance analysis based on such parameters is straightforward, because it is based on the comparison between measurements and predictions. Unfortunately, the large number of unpredictable conditions, which affect the performance of solar panels, poses a serious challenge to the definition of a reliable target for the expected outputs [13]. The knowledge on the characteristics of solar photovoltaic modules under real operating conditions is of great importance in determining their performance [6].

The performance of a solar PV system is related to environmental conditions and PV system parameters. The output power generated from a solar PV system highly depends on the amount of solar radiation absorbed by the solar cells on a PV module. Due to variations of the sun's position each day and the apparent motion of the sun throughout the year, the total irradiation received at a particular site is different from time to time. Therefore, the output power of a PV system will vary with time. In addition to the inherent factor due to the sun's position/motion, other known factors affecting performance include ambient temperature, cell temperature, and local climate conditions [12]. Solar radiation data provide information on how much of the sun's energy strikes a surface at a location on the earth during a particular time period [14].

This paper presents a real-time daily measurements for such modules that serve the system design, prediction, and modeling. Single and multi-panel connection categories are used as a platform to test the PV system at various temperature and irradiance ranges. Experimental measurements for modeling. Thin-Film panels were conducted at UPM University, Serdang, Malaysia, where a 6 different modules are tested according to their interconnection and installation. A wireless data acquisition card with one second sampling interval for the two weather and two channels for the electrical parameters (Voltage and Current) and environmental parameters (light intensity and temperature), thus, the PV system energy output is primarily influenced with these parameters by according to weather conditions. Axiomatically, it's supposed to have different efficiency.

\section{EXPERIMENTAL SETUP AND METHODOLOGY}

\subsection{Measurements of Thin Film Solar PV Panels}

The experimental work has been conducted on Thin-Film solar panels available in Electrical and Electronics, Engineering Faculty of UPM University, Malaysia. The setting up of mechanical structure that carries the panels and arranges the interconnections for 6-panels, each of a two panels they have a same transparency ratio $(40 \%, 20$, and $10 \%)$ all the panels have the same dimensions $(1200 \mathrm{~mm} \times 800 \mathrm{~mm} \times 60 \mathrm{~mm})$. 
The setting up of mechanical structure that carries the panels and arranges the interconnections shown in Figure 1.

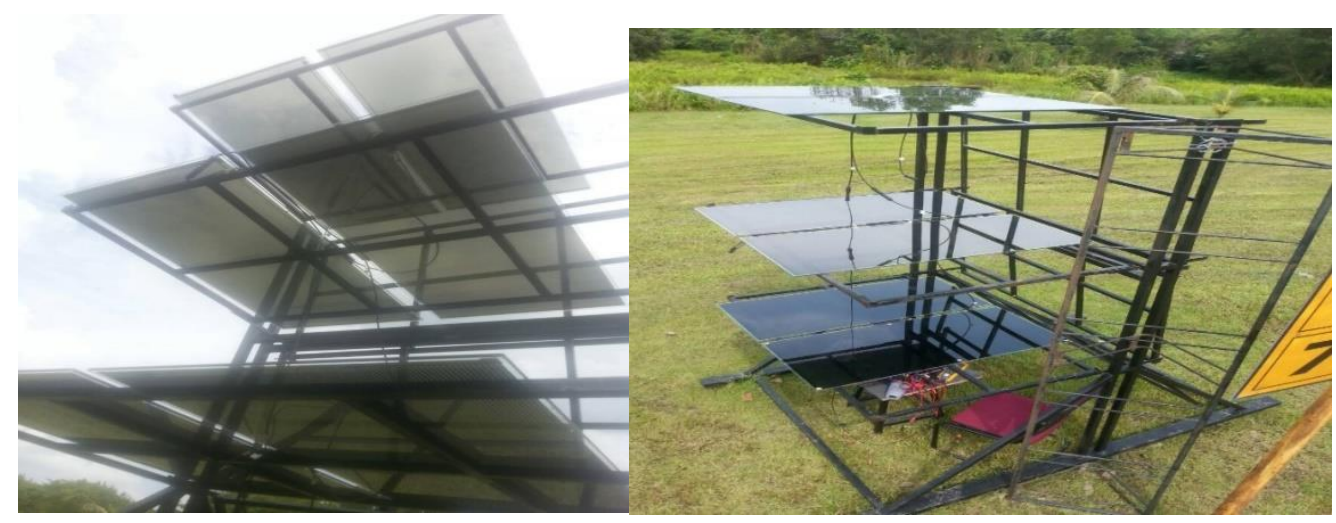

Figure 1. Thin film solar PV panels installed in the UPM University.

The data testing are collect of the solar panels be for several days on an hourly basis from 7am to $7 \mathrm{pm}$ through by a network of wireless is consisting of two circuits: the outer circuit at the site (UPM field) where it contains some sensors. The current sensor, voltage, irradiance, and temperature sensor are measuring the output of each individual PV and sends it to the coordinator by using a wireless for communication. On the other hand, the coordinator's sensor is connected in the inner circuit that placed in the lab with a computer to receive the data (The measured voltage, current, irradiance, and temperature).

During the measurement, the panel's holder was not changing locations. By doing this the effect of changes in the ambient environment to the measurement process. During the measurements, the following parameters were recorded: date, time of measurement, weather conditions (percent cloud cover), the amount of incident light $\left[\mathrm{w} / \mathrm{m}^{2}\right]$, the ambient air temperature $\left({ }^{\circ} \mathrm{C}\right)$ the relative humidity [RH\%]. We've taken several a measurements for six panels, also three and two panels are connected by series as measurements for the multi panel. While for single panel measurements were used as one panel. Supplying power to a variable resistor by battery as well it feeds the outer circuit, considered as a resistor load is constant. As shown in Figure 2. (a) and (b).

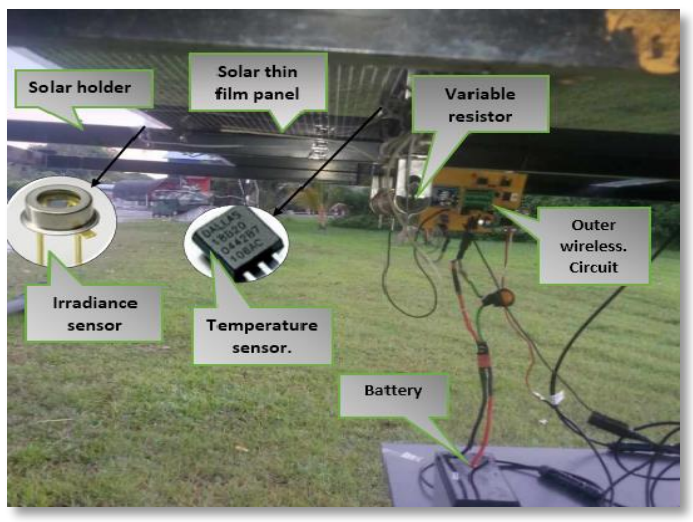

(a)

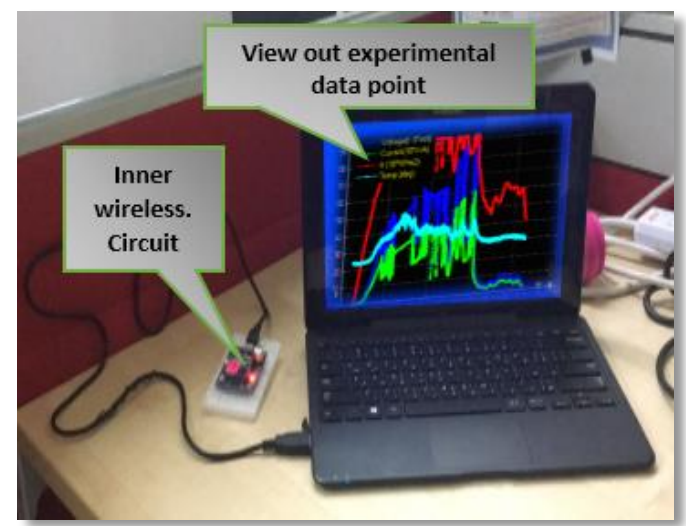

(b)

Figure 2. Monitoring of system and experimental measurements of setup (a) the outer circuit (UPM field, (b) inner circuit (lab).

\subsection{System objectives}

The system was develop for measuring and monitoring a PV module. It provides facilities to get the test through three types of measurements; Environmental and system variables (ambient temperature, solar 
irradiance, voltage, current, energy, power). The Passive sampling uses simple equipment but it does not provide the real time values. The procedure of continuous online monitoring uses sensors to monitor the parameters, and then send to control center by network. The way of data transfer includes wired and wireless systems [15].

Monitoring and analyzing of these parameters will make the system appropriate to carry out relevant duty as described:

1. Complete reports about production cycles supporting a collection of tools to plan the activity and the power production.

2. Real-time monitoring of the effective energy power produced by each solar panel and, obviously, by the entire system, according to the solar irradiation and environmental conditions.

3. Measuring solar radiation in real time to optimize the display of panels with estimate to solar irradiation. Valuation, through historical data stocked by the system and weather predication per day, the production of energy. As shown in Figure 3.

4. Specific and real-time conservation through by the individualization of a final inactivity in short time.

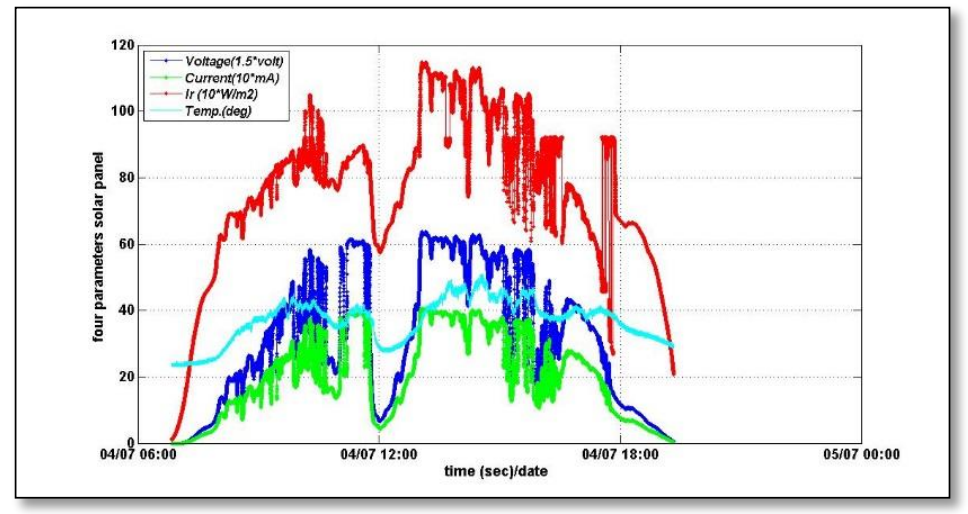

Figure 3. The four parameters of solar thin-film with a time period.

Several measurements were collected under different weather conditions and can be listed as in table 1.

Table 1. Experimental measurements of solar PV panels at real time

\begin{tabular}{|c|c|c|c|c|c|}
\hline \multirow{2}{*}{ Structure } & \multirow{2}{*}{ Transparency } & \multicolumn{2}{|c|}{ Data testing } & \multicolumn{2}{|c|}{ Weather conditions } \\
\hline & & date & Time & Ambient air Temp. & Humidity RH \\
\hline 6 panel & $\begin{array}{c}\text { Each 2p } \\
(40,20,10) \%\end{array}$ & $19^{\text {th }}$ June 2017 & 7:15am-7:20pm & $\begin{array}{c}34 \mathrm{c} \\
\text { partly cloudy/sunny }\end{array}$ & $50 \%$ - $83 \%$ \\
\hline 3 panel & $(40,20,10) \%$ & $1^{\text {st }}$ July 2017 & 6:44am -6:44pm & $\begin{array}{c}35 \mathrm{c} \\
\text { cloudy/raining }\end{array}$ & $49 \% \_86 \%$ \\
\hline 3 panel & $(40,20,10) \%$ & $2^{\text {nd }}$ July 2017 & 7:01am -7:30pm & $\begin{array}{l}32 \mathrm{c} \\
\text { partly cloudy }\end{array}$ & $47 \% \_89 \%$ \\
\hline 2 panel & $(40,20) \%$ & $29^{\text {th }}$ June 2017 & 6:32am-7:32pm & $\begin{array}{c}37 \mathrm{c} \\
\text { partly cloudy/sunny }\end{array}$ & $57 \% \_86 \%$ \\
\hline 2 panel & $(40,20) \%$ & $30^{\text {th }}$ June 2017 & $6: 32 \mathrm{am}-6: 32 \mathrm{pm}$ & $\begin{array}{c}34 \mathrm{c} \\
\text { cloudy/raining }\end{array}$ & $48 \% \_75 \%$ \\
\hline 1 panel & $40 \%$ & $4^{\text {th }}$ July 2017 & 6:50am -7:20pm & $\begin{array}{c}34 \mathrm{c} \\
\text { partly cloudy /rain }\end{array}$ & $48 \% \_89 \%$ \\
\hline 1 panel & $40 \%$ & $5^{\text {th }}$ July 2017 & 7:00am -7:19pm & $\begin{array}{c}33 \mathrm{c} \\
\text { cloudy /sunny }\end{array}$ & $56 \% \_91 \%$ \\
\hline
\end{tabular}

Daily measurements show the relationships between the output power (voltage V, and current I) and, in contrast, the variations in the irradiance and temperature (Irr, T) and all of them based on the time axis, the attained daily data for several days were collected as the data sheet excel. 


\section{RESULTS AND ANALYSIS}

Decomposition model is analyzed with different time periods of samples and for different forecasting intervals. Several cases were tested for different climatic conditions. A data set of solar irradiance for two month is considered for these case studies which are discussed below. Since the data size is huge, the data is averaged over 10 min intervals.

This work has been undertake during a rainy and cloudy season. There was hardly a clear and cloudless sky on the day of even a single test. The reliance of efficiency of solar cells on seasons has been reported by many researchers [9]. We used measurements of PV power output of thin film PV panel for the multi panel (three panels connecting by series, two panels are connecting by series) as well as measured single panel power input (solar Irradiance)measurements versus time and power output (Vx I)measurement data test versus Time, as classified them as follows

\subsection{Experimental measurements of solar thin film for multi - panel ( 2 or 3 panel connecting by series)}

The results to the base on the collected data, the correlation between the amount of the incident light $\left[\mathrm{w} / \mathrm{m}^{2}\right]$ and the output of the electric power [watt].

1. The solar measurements (2panel) are taken on 30th June 2017 as Figure 4.

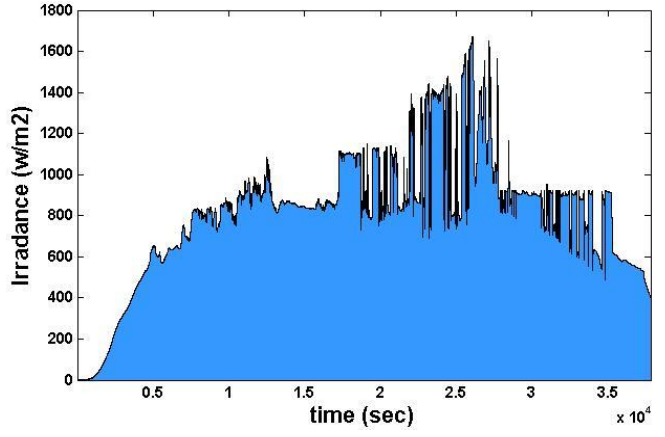

(a)

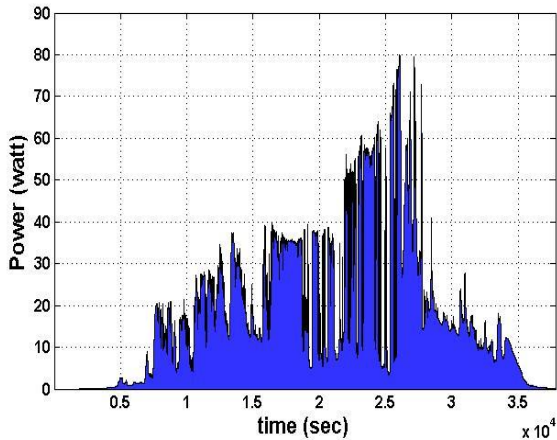

(b)

Figure 4. The harvested energy for 2 panels in $30^{\text {th }}$ June (E_2p30 $\left.0^{\text {th } J u n ~}(w / h)\right)$. (a) Solar irradiance input power (Eirr) with the time. (b) Solar output power (Eout) with time.

2. The solar measurements (3panel) are taken in $2^{\text {nd }}$ July 2017 as Figure 5.

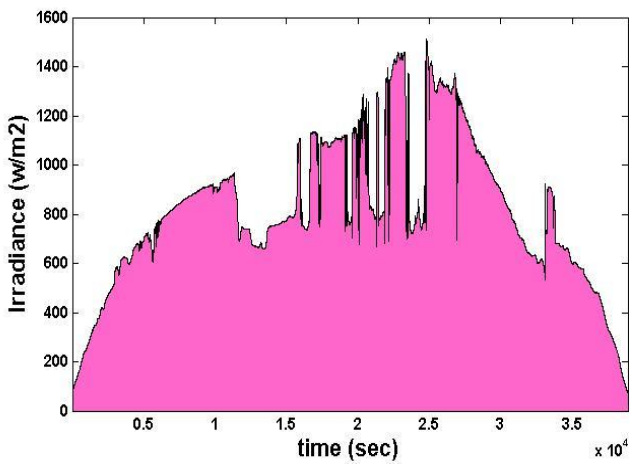

(a)

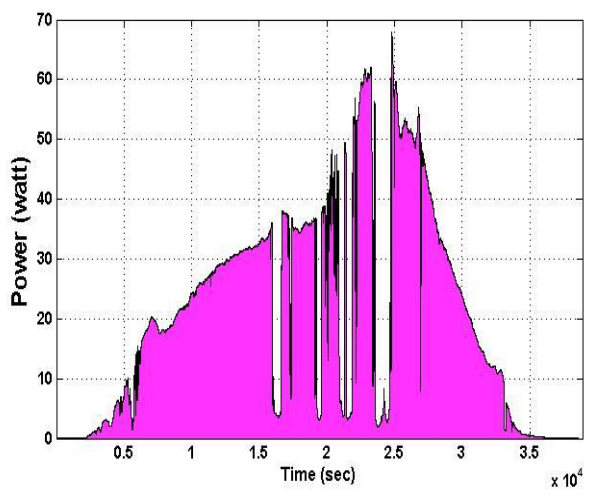

(b)

Figure 5. The harvested energy of 3 panels in $2^{\text {nd }} J u l y\left(E \_2 p 2^{\text {nd }} J u l y(w / h)\right)$. (a) Solar irradiance input power (Eirr) vs time. (b) Solar output power vs time. 
3.2. Experimental measurements of solar thin film for single - panel

1. The solar thin-film measurements are taken in 5th July 2017 as Fig.6.

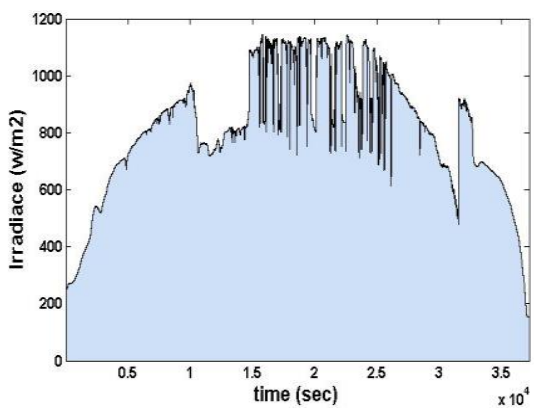

(a)

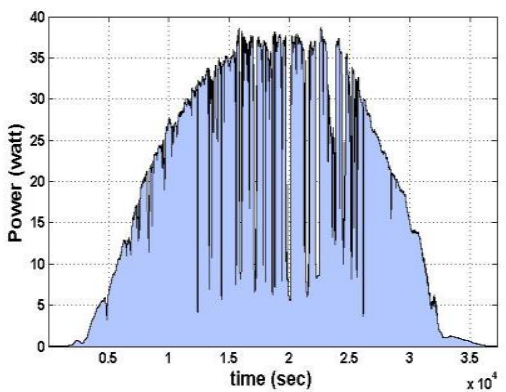

(b)

Figure 6. The harvested energy of single panel in $5^{\text {th }} \mathrm{July}\left(\mathrm{E} \_1 \mathrm{p} 5^{\text {th } J u l y}(\mathrm{w} / \mathrm{h})\right)$. (a) Solar irradiance input power vs time. (b) Solar output power with the time.

\subsection{Measuring solar energy and Efficiency}

The Efficiency in photovoltaic solar panels is measured by the ability of a panel to convert sunlight into serviceable energy for human consuming. Knowing the efficiency of a panel is important in order that select the valid panels for your photovoltaic system. The panel efficiency define the power output of a panel per unit of panel area.

The efficiency of solar panels can be defined as the ratio of electric power generated by photovoltaic panels (power output) and the power to be transmitted into the photovoltaic panel through insolation (the power input). This relation is calculated as follows: Solar efficiency $(\eta)=$ Power output / Solar irradiance Panel *Area. As there is a relationship between output power and solar irradiance: The Solar efficiency $(\eta)=$ Output energy/Input energy $x 100$.

Input energy Eirrd (w/h) have represented which energy absorbed by solar panel of sunlight, the solar radiation multiply area. From Ohm's law: - Power out (watt) = V x I, also we can be calculated data of power (watt) versus time of day (sec).

The quantity of energy [Eout $(\mathrm{W} / \mathrm{h})]$ which is equal to the area under the power rate curve as indicated it in Fig. 7.

$$
\text { Eout }=\int_{7 a m}^{7 p m} P(t) d t
$$

$E_{\text {out }}(w / h)$ representing the power output of solar panel during an hour day.
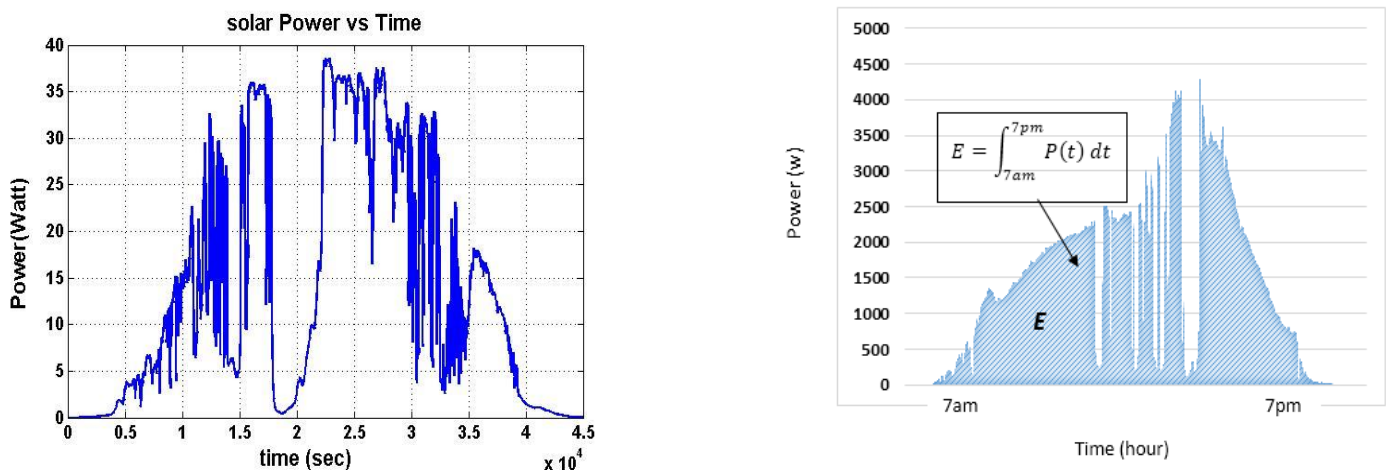

Figure 7. Amount Solar energy during a day. 
Input energy Eirrd (w/h) have represented which energy absorbed by solar panel of sunlight, the solar radiation multiply area.

Table 2. The Montering results of energy produced and efficiency from solar thin film semitransparent

\begin{tabular}{|c|c|c|c|c|}
\hline Thin film solar PV & $\begin{array}{l}\text { Number of } \\
\text { panel/date }\end{array}$ & $\begin{array}{c}\text { Energy output } \\
{[\text { Eout }(\mathrm{w} / \mathrm{h})]}\end{array}$ & $\begin{array}{c}\text { Energy } \\
\text { Input [Eirr }(\mathrm{w} / \mathrm{h})]\end{array}$ & $\begin{array}{c}\text { Solar } \\
\text { Efficiency } \eta\end{array}$ \\
\hline Single solar panel & $\begin{array}{c}\text { 1panel_5 } 5^{\text {th }} \\
\text { July } \\
\text { (E_1P5July) }\end{array}$ & 190.01 & 8365.95 & 2.271 \\
\hline $\begin{array}{l}\text { Multi solar panel } \\
\quad \text { (2panels) }\end{array}$ & $\begin{array}{c}\text { 2panel_30 } \\
\text { June } \\
\text { (E_2P30June) }\end{array}$ & 186.138 & 8469.79 & 2.1977 \\
\hline $\begin{array}{l}\text { Multi solar panel } \\
\quad \text { (3panels) }\end{array}$ & $\begin{array}{c}\text { 3panel_2 } 2^{\text {nd }} \\
\text { July } \\
\text { (E_3P2July) }\end{array}$ & 218.48 & 8749.3 & 2.51 \\
\hline
\end{tabular}

The table II represent the monitoring result measured of solar PV thin film and predicted time and data of testing are given for each case study of solar PV individually.

The single PV panel's results were on recorded by the monitoring system during the day. This result offered the output efficiency for the single PV panel and for an array which included multiple PV panels. the instantaneous output power created by the PV system will be changing with time as the solar irradiation absorbed by PV panels change from morning to night, the describes the daily profiles of output power generated from the PV system during the day. These days were chosen to cover the changing weather patterns as widely as possible.

We note the different of output, input energy quantities and efficiency of semi-transparent solar thin film due to weather conditions and a number of panels (single or multi panel) as Figures 8 and 9.

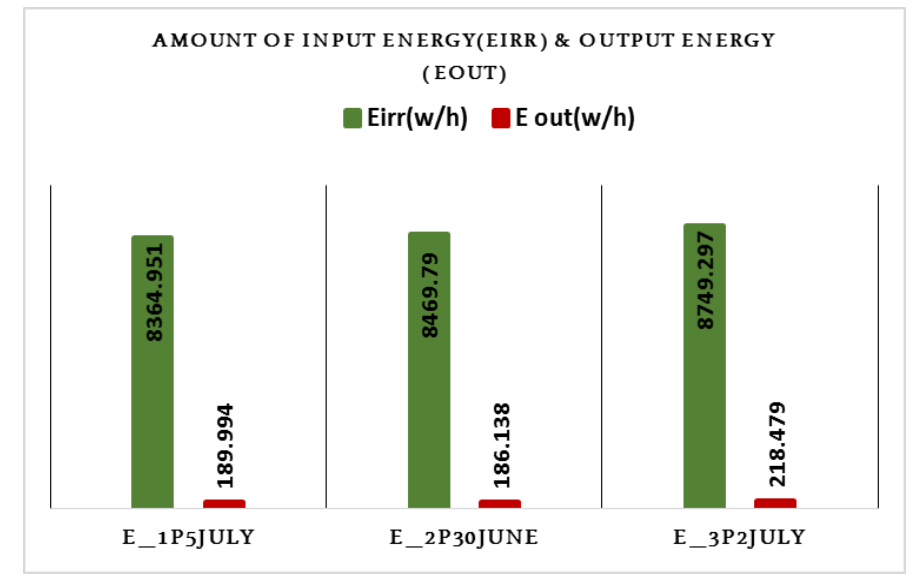

Figure 8. Quantities of energy (out and input energy).

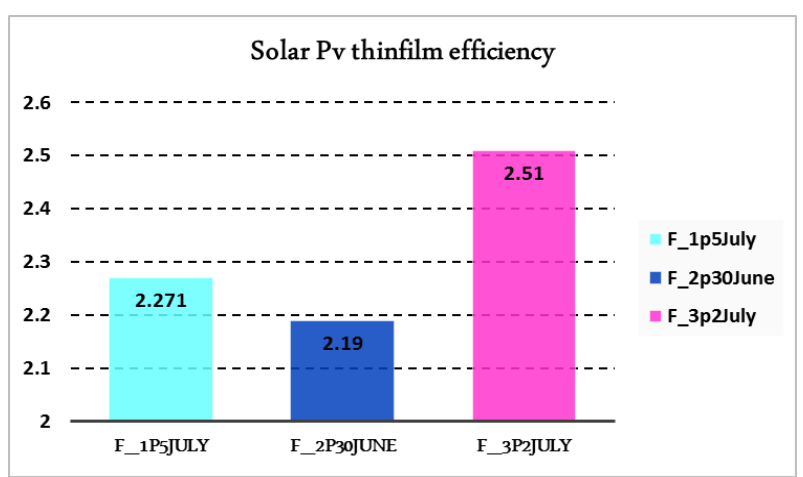

Figure 9. Solar Efficiency for 4 study cases of solar thin film measurements. 
Based on the measured values of electrical and physical parameters monitored for the semitransparent thin film photovoltaic panels installed in the UPM university field, it is possible to conclude as follows. We've selected two related research articles that may very benefit the achievement of this work [16] - [17], because they considered the solar PV array as the only power supply to feed electricity to a high efficient home system with DC environment. Electrical power output of the semitransparent thin film solar panels increases with increasing of the light intensity on the panels during time period of one day .The obtained efficiency of the thin film solar multi panels( 2 panel by series) was about $2.19 \%$ lower than the single panel efficiency have $2.27 \%$.

\section{CONCLUSION}

The output power and efficiency of a solar PV system are not constant but changes over time each day. The daily changing styles provide valuable on-line information for users and designers for analyzing the performance of their solar PV system. The objective of this paper was to develop a real time prediction model for daily and monthly average accurately power output as well as an on-line assessment model for system efficiency.

The suggested prediction model can serve a useful purpose for the real time prediction of system efficiency for a solar PV system. This paper analyzes the electrical characteristics of thin film solar panels in the assignment of changes of the microclimate conditions. Based on the results, the calculated efficiency is obtained as the proportion of the input of sun energy and the output of electrical energy. Based on the measured values of electrical and physical parameters monitored for the semitransparent thin film photovoltaic panels installed in UPM university field, it is possible to infer as follows. The electrical power output of the semitransparent thin film solar panels increases with increasing of the light intensity on the panels during time period for one day. The obtained efficiency of the thin film solar multi panels (two panel connecting by series) was about $2.19 \%$ lower than the single panel while $2.27 \%$. The performance of the Thin-Film PV is highly affected by weather conditions which are similar to the normal Silicon-based solar panel. The individual efficiency of the panel is higher than when they are installed in layer mode, nevertheless the electrical connection in parallel or series, the overall power would be higher

\section{REFERENCES}

[1] V. Lo, A. Orioli, and G. Ciulla, "Solar Energy Materials \& Solar Cells On the experimental validation of an improved five-parameter model for silicon photovoltaic modules," Sol. Energy Mater. Sol. Cells, vol. 105, pp. 27$39,2012$.

[2] A. Kurjakov, M. Kurjakov, D. Miškovi, and M. Cari, "electrical characteristics of thin film solar panels on a river boat under different," vol. 25, no. August, pp. 151-160, 2012.

[3] G. Aiello, S. Alfonzetti, S. A. Rizzo, and N. Salerno, "Multi-Objective Optimization of Thin-Film Silicon," Energies, 2017.

[4] Y. Chu, "Review and Comparison of Different Solar Energy Technologies August 2011 Table of Contents," 2011.

[5] V. P. Sethi, K. Sumathy, S. Yuvarajan, and D. S. Pal, "Mathematical Model for Computing Maximum Power Output of a PV Solar Module and Experimental Validation," J. Fundam. Renew. Energy Appl., vol. 2, pp. 1-5, 2012.

[6] B. Balasubramanian, A. M. Ariffin, and S. H. Al-zubaidi, "Assessment of Simulation Modelling and Real-Time Measurements for 3.15 and 17 .28 kWp Solar Photovoltaic ( PV ) Systems in Malaysia," vol. 7, no. 1, 2017.

[7] V. Prema and K. U. Rao, "Development of statistical time series models for solar power prediction," Renew. Energy, vol. 83, pp. 100-109, 2015.

[8] A. Ibrahim, "Analysis of Electrical Characteristics of Photovoltaic Single Crystal Silicon Solar Cells at Outdoor Measurements," Smart Grid Renew. Energy, vol. 2011, no. May, pp. 169-175, 2011.

[9] M. J. Prieto, A. M. Pernía, F. Nuño, J. Díaz, and P. J. Villegas, "Development of a Wireless Sensor Network for Individual Monitoring of Panels in a Photovoltaic Plant," sensors ISSN, pp. 2379-2396, 2014.

[10] C. Huang, M. Huang, and C. Chen, "A Novel Power Output Model for Photovoltaic Systems," Int. J. Smart Grid Clean Energy A, 2012.

[11] M. Benghanem, "A low cost wireless data acquisition system for weather station monitoring," Renew. Energy, vol. 35, no. 4, pp. 862-872, 2010.

[12] Y. Su, L. Chan, L. Shu, and K. Tsui, "Real-time prediction models for output power and efficiency of gridconnected solar photovoltaic systems," Appl. Energy, vol. 93, pp. 319-326, 2012.

[13] S. Daliento et al., "Monitoring, Diagnosis , and Power Forecasting for Photovoltaic Fields : A Review," Int. J. Photoenergy, vol. 2017, 2017.

[14] T. Khatib, A. Mohamed, K. Sopian, and M. Mahmoud, "Solar Energy Prediction for Malaysia Using Artificial Neural Networks," Int. J. Photoenergy, vol. 2012, 2012.

[15] V. K. Ustad and S. S. Kibile, "Zigbee Based Wireless Air Pollution Monitoring System Using Low Cost," Int. J. Eng. Trends Technol., vol. 10, no. 9, pp. 456-460, 2014.

[16] A. H. Sabry, W. Z. Wan Hasan, M. Zainal, M. Amran, and S. B. Shafie, "DC Loads Matching Technique as an 
Alternative to AC Inverter in Residential Solar System Application Evaluation and Comparison,” Appl. Mech. Mater., vol. 785, pp. 225-230, 2015.

[17] A. H. Sabry, W. Zuha, W. Hasan, M. Zainal, M. Amran, and S. B. Shafie, "high efficiency integrated solar home automation system based on dc load matching technique," ARPN J. Eng. Appl. Sci., vol. 10, no. 15, pp. 6424-6434, 2015.

[18] M.H.M. Sidek, N. Azis. W.Z.W. Hasan, M.Z.Ab Kadir, S. Shafie and M.A.M. Radzi, "Automated positioning dualaxis solar tracking system with precision evelation and azimuth angle control” Energy (74) 2017 pp 302-30

[19] A. A. F. Husain and W. Z.Wan Hasan,"Transparent Solar Cell Using Spin Coating and Screen Printing" Pertanika J. Sci. \& Technol. 25 (S) 2017, pp 225 - 234

[20] A. H. Sabry W. Z. W. Hasan, MZA Ab. Kadir, M. A. M. Radzi, and S. Shafie," Photovoltaic-Powered Smart Home System with Direct Current-Environment", Journal of Computational and Theoretical Nanoscience (ASP) Vol. 14, $1-16,2017$

[21] Ahmad H. Sabry, W. Z. W. Hasan, M.Z.A. Ab Kader, M. A. M. Radzi, S. Shafie, "Field Data-based Mathematical Modeling by Bode Equations and Vector Fitting Algorithm for Renewable Energy Applications", PLoS ONE 12(9), 2017.

[22] M.M.M. Hanifah, H. Zainuddin and M.Z. Hussin, "Evaluation of Standard Reference Environment for Photovoltaic Nominal Operating Cell Temperature Testing in Malaysia," Indonesian Journal of Electrical Engineering and Computer Science, 8(1), pp.245-252, 2017. 